\title{
A Comparative Study to Assess the Rates on the Recovery of Covid-19 Patients With or Without Comorbidities in A Tertiary Care Hospital
}

\author{
${ }^{1}$ Dr. Jayaprakash.K, ${ }^{2}$ Dr. P.Sharmila Nirojini, ${ }^{* 2}$ Neeya Johny, ${ }^{2} \mathrm{~S}$. Niranjana, ${ }^{2}$ Neenu Wilson, ${ }^{2} \mathrm{~T}$. Nivashini, ${ }^{2} \mathrm{~S}$. Pavithra \\ 1. Vivekanandha Medical Care Hospital, Elyampalayam, Tiruchengode, Tamil Nadu, India. \\ 2. Department of Pharmacy Practice, Swamy Vivekanandha College of Pharmacy, Tiruchengode, Namakkal (Dt.) Tamil Nadu, India. \\ *Corresponding author's E-mail: neeya.johny333@gmail.com
}

Received: 10-08-2021; Revised: 26-09-2021; Accepted: 03-10-2021; Published on: 15-10-2021. \begin{abstract}
Coronavirus disease of 2019 (COVID-19) is a highly contagious infectious disease which lead to a global pandemic. This virus attacks the small blood vessels, endothelial linings and lead to impaired blood flow and vessel malfunctioning's in various organs. This explains the reason why the high vulnerability patient population is those with comorbidities like hypertension, diabetes, COPD, obesity and cardiovascular diseases. The objective of the study was to compare the rates of recovery in the comorbid Covid-19 patient population when compared to those without comorbidities by evaluating their CT Chest - Score, RT- PCR, duration of hospitalization and thereby assess if the quality of life was compromised. A Prospective Observational Study was conducted for a period of 4 months with over 400 laboratory-confirmed Covid-19 patients. Out of the 400 patients, considering the exclusion and inclusion criteria 191 moderately ill covid-19 patients with or without comorbidities were included in the study. The severity of the patients was assessed based on the CT- Chest Score and COVID-19 RT-PCR reports. Various other complications faced by comorbid patients when compared to patients with nil comorbidities were also investigated. In our study among the underlying comorbidities, the most common were DM (40.11\%), HTN (35.32 \%), CAD (7.78 \%), COPD (6.58 \%), CKD (5.38 \%) and then hypothyroidism (4.79\%). Our study also concluded that the percentage of patients with a comorbid condition was higher (59.68\%) than those without a comorbid condition (40.31\%). The mean reduction in CT-Score in the comorbid and nil-comorbid was found to be $9.38 \pm 2.85$ and $7.08 \pm 2.89$. The mean reduction in hospital stay in the comorbid and nil comorbid group was found to be $9.50 \pm 2.34$ and $8.08 \pm 1.71$. The mean reduction in RT-PCR was $10.04 \pm$ 2.95 and $7.44 \pm 2.33$ in the comorbid and nil comorbid group respectively. Therefore, the RT-PCT, duration of hospital stay and CTChest Score showed a statistical significance of $p$-value $<0.0001$. The study concludes that the comorbid patients when compared to those without comorbidities had a longer hospital stay and more time for recovery which led to a compromise in their health status.
\end{abstract}

Keywords: COVID-19 patients, SARS COV-2, Comorbidity, CT- Chest Score, RT-PCR, Recovery rate.

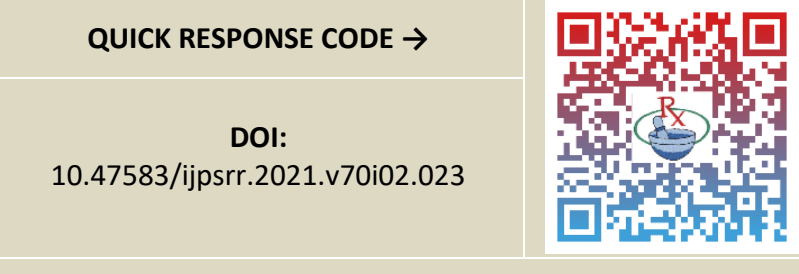

DOI link: http://dx.doi.org/10.47583/ijpsrr.2021.v70i02.023

\section{INTRODUCTION}

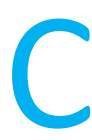

oronavirus disease of 2019 (COVID-19) is a highly contagious infectious disease which lead to a global pandemic. It initially originated from the wet markets of Wuhan, China, and spread rapidly to over 180 countries and raised a serious threat to public health. The severe acute respiratory syndrome coronavirus 2 (SARSCoV2), which is the causative agent of the COVID-19 belongs to the coronaviridae family. ${ }^{1}$ The SARS viruses were commonly known to infect animals but under certain conditions, the viruses may cross-species barrier and infect humans as well. The seven coronavirus species that are identified to date to infect human beings are the HCoV229E, HCoVOC43, HCoV-NL63, and HCoV-HKU1. These are generally mild and often tend to cause only normal flu-like symptoms. $^{2}$ Meanwhile, the other three human coronaviruses, namely the Middle East Respiratory
Syndrome-related coronavirus (MERS-CoV), severe acute respiratory syndrome coronavirus (SARS-CoV) and severe acute respiratory syndrome coronavirus 2 (SARS-CoV-2) may tend to produce other serious symptoms. ${ }^{3}$ The common signs and symptoms of the infection include fever, breathing difficulties, cough, headache, fatigue, loss of taste or smell and myalgia. In severe cases, the infection can cause pneumonia, severe acute respiratory syndrome, multiple organ failure and even death. ${ }^{4,5,6}$

This virus attacks the small blood vessels, endothelial linings and lead to impaired blood flow and vessel malfunctioning's in various organs. This explains the reason why the high vulnerability patient population is those with comorbidities like hypertension, diabetes, COPD, obesity and cardiovascular diseases. Few renal histopathological findings of COVID-19 patients showed damaged endothelium and several other studies have shown the presence of inflammatory cells and viral elements within the endothelial cells of the COVID-19 patients. ${ }^{7}$ Some post-mortem samples of COVID-19 patients showed bilateral diffuse alveolar damage with cellular fibromyxoid exudates and pulmonary oedema. Hence, the multiple organ failure observed in COVID-19 patients may be due to the damaged endothelium caused 
by either direct virus infection or immune cells recruitment to the site of infection. ${ }^{8}$

The old aged and those of any age with a comorbid condition, such as hypertension and diabetes, are the most affected and have shown worse prognosis. The age-related physiologic changes in the geriatric population may also lead to a reduction of lung reserve, reduction of airway clearance and reduction of the defense barrier function. ${ }^{9,10}$ Studies have shown that morbidity and mortality rates were higher in the diabetic and hypertensive group and have been linked to more duration of hospitalization and intensive care unit (ICU) admissions. ${ }^{11}$ People with chronic obstructive pulmonary disease (COPD) or any associated respiratory illnesses were seen to be at higher risk for severe illness from COVID-19 than those without any comorbid conditions. ${ }^{12,13}$ Therefore, the older age especially those above 60 years and those with any other underlying health conditions may experience slightly severe symptoms leading to delayed recovery when compared to those without any comorbid conditions. ${ }^{14,15}$

\section{METHODOLOGY}

\section{Study site}

This study was conducted at the Department of Emergency Medicine, Vivekanandha Medical Care Hospital, Elayampalayam, Tiruchengode, Tamilnadu, India

\section{Study design}

A hospital-based prospective observational study to assess the rates on recovery of covid-19 patients with and without comorbidities was conducted in a tertiary care hospital.

\section{Sample size}

A total of 400 patients with laboratory-confirmed SARSCoV-2 infection was screened, among which 191 patients during their time of admission were included in our study who fulfilled the exclusion and inclusion criteria.

\section{Study duration}

The study was conducted for a period of 4 months from October 2020 to January 2021.

\section{Study criteria}

The study carried out by considering the following criteria:

\section{Inclusion criteria}

All the patients admitted in the emergency medicine department with covid 19 symptoms.

\section{Exclusion criteria}

Pregnant and lactating women positive for SARS COV -2

COVID-19 Positive patients who preferred home quarantine

Mildly positive COVID-19 patients

\section{Ethical approval}

This study was approved by the Institutional Ethical Committee held on 03-10-2020 at Vivekanandha Medical Care Hospital, Elayampalayam, Tiruchengode, Tamilnadu, India with Ethical Committee numberSVCP/IEC/OCT/2020/42.

\section{Data analysis}

The data collected was analyzed to assess the possible comorbidities. The severity of illness in the patient population was assessed based on the CT Chest Score (inbetween 8-16) and COVID-19 RT-PCR reports. The CT Chest score was used to identify to what extend the lung was affected due to the infection and also to predict the development of pneumonia and lung damage.

\section{Statistical Analysis}

Statistical analysis of the collected data was done using Graph Pad Instat version 3.10. Mean \pm standard deviation was used to express the values. The student t-test was used to compare the baseline and endpoint levels within each group and also to obtain the mean differences and the standard deviation between the groups. A P-value of less than 0.05 were considered to be statistically significant.

\section{RESULTS}

\section{Gender Distribution of Covid-19 Patients}

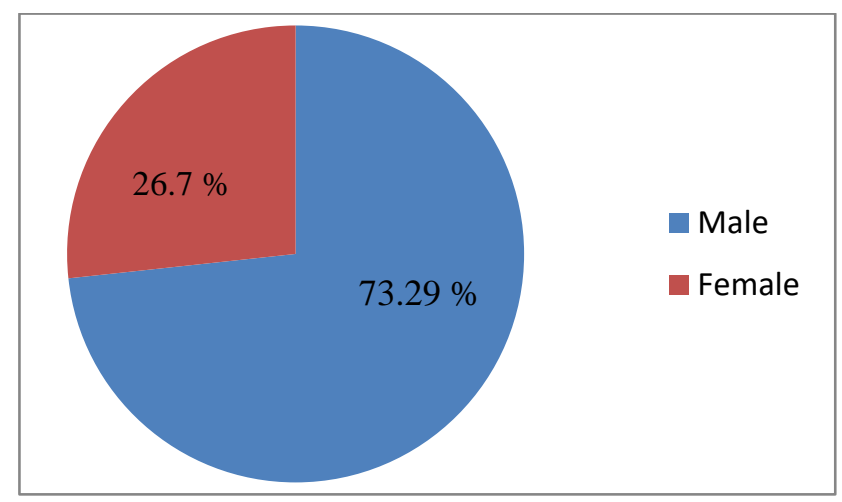

Figure 1: Gender distribution in percentage

Among the 400-patient population screened, 191 patients were included in our study based on the inclusion and exclusion criteria and it was observed that males were higher in number when compared to females. Gender distribution in percentage among the study population showed $73.29 \%$ were males and $26.7 \%$ were females.

\section{Age Distribution in Covid-19 Patients}

COVID-19 infection was found to be more prevalent among the age group of $51-60(26.17 \%)$ years and the least were in the age group between 21-30 (2.09\%) years. The observed results may also indicate that the risk in the severity of illness with COVID-19 could increase with age, with older adults at the highest risk primarily due to certain physiological changes or other underlying medical 
conditions that make them more susceptible to the infection.

\section{Complaints on Admission}

In this study, fever and cough were found to be the most common complaints presented by the subjects on admission with a total percentage of $20.91 \%$ and $16.73 \%$ respectively and running nose was the least observed with $0.8 \%$. However, mostly the signs and symptoms may begin only after the incubation period of 2 to 14 days. Early signs of COVID-19 may include fever, cough, tiredness and loss of taste or smell. Other symptoms include breathing difficulty, myalgia, sore throat, headache, running nose, chest pain, vomiting and diarrhoea. In some severe cases, the infection may cause pneumonia, severe acute respiratory syndrome and even death.

\section{Complaints during the treatment}

In this study, most of the complaints presented by the patients on admission were improved during the course of treatment and the patients were gradually recovering.

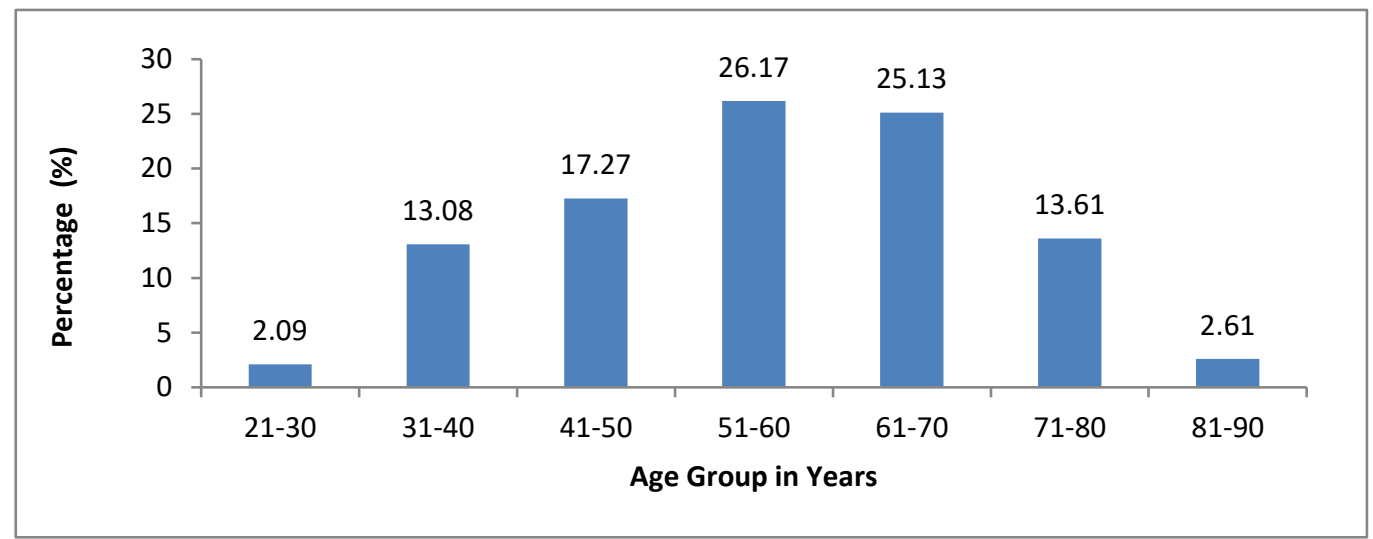

Figure 2: Age distribution in percentage

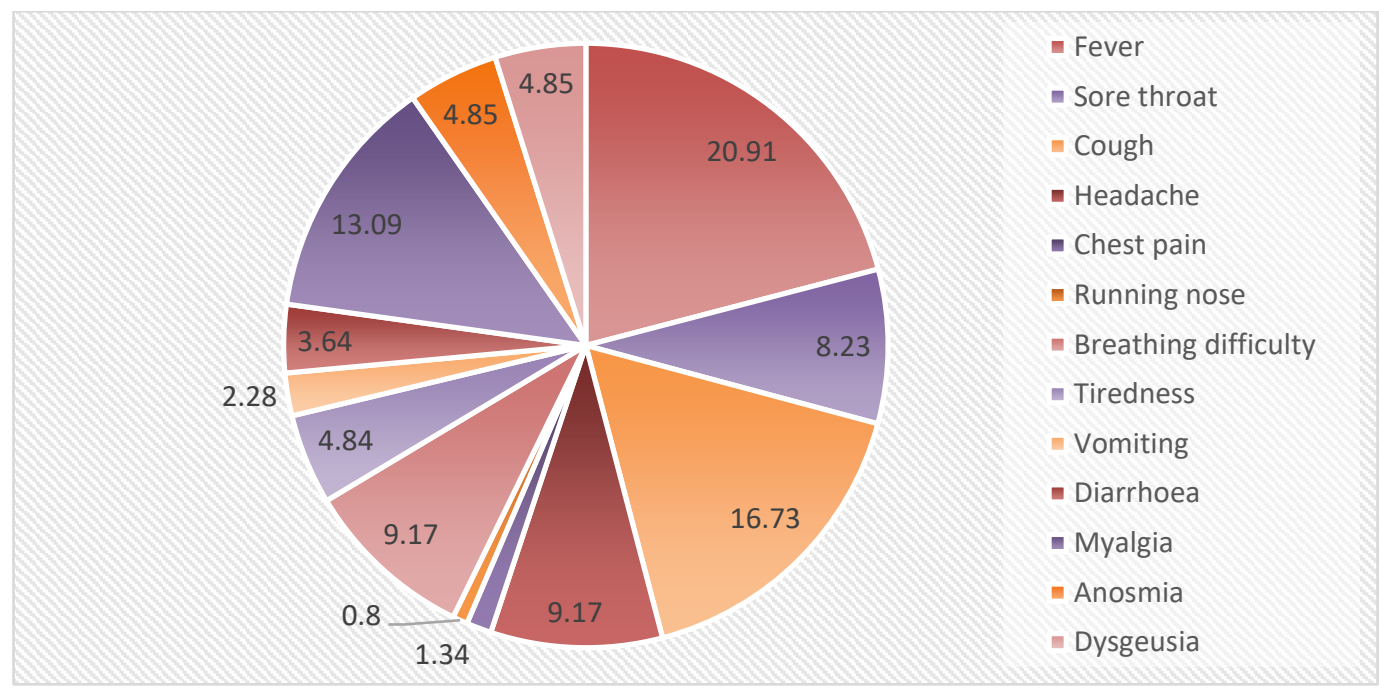

Figure 3: Complaints on admission in percentage

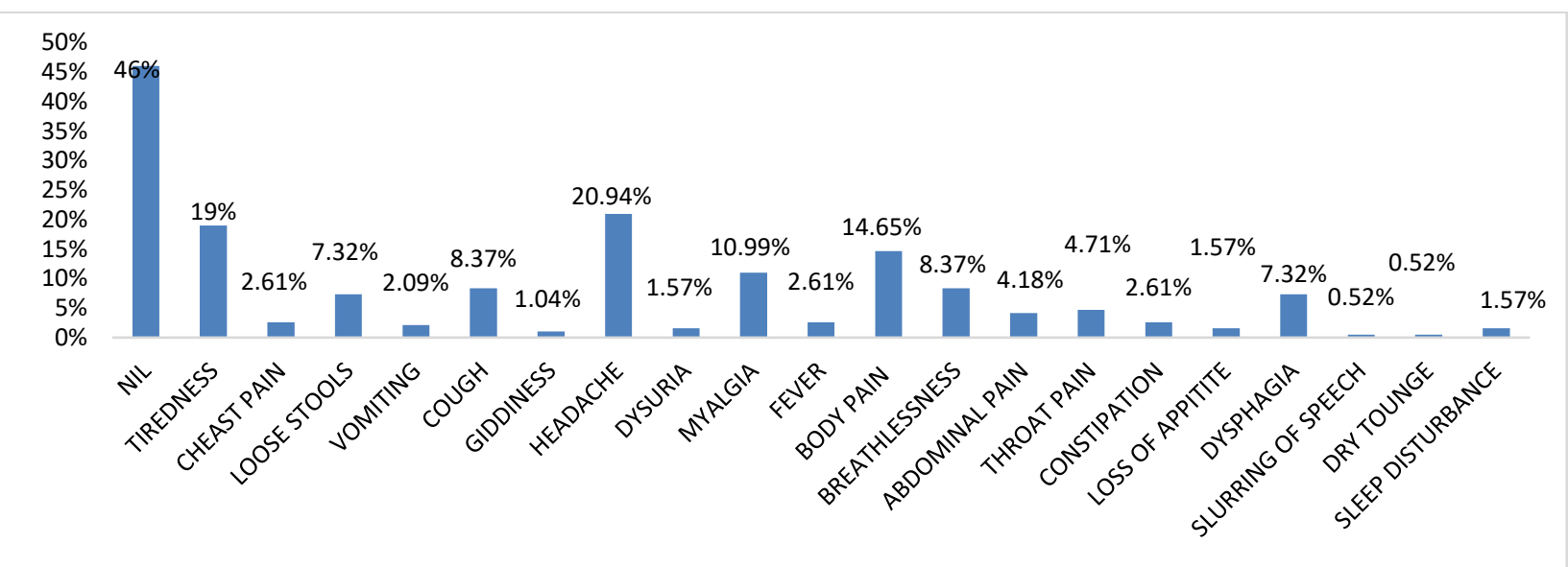

Figure 4: Complaints of the patients during the treatment 
However, some during the course of treatment were also presented with complaints of headache (20.94\%), tiredness (19 \%), body pain (14.65\%), myalgia (10.99\%), breathlessness (8.37\%), cough (8.37\%), dysphagia (7.32\%), loose stools $(7.09 \%)$, throat pain $(4.71 \%$,)abdominal pain (4.18\%), fever (2.61\%), constipation (2.61\%), chest pain (2.61\%), vomiting (2.09\%), sleep disturbance (1.57\%), loss of appetite (1.57\%), dysuria (1.57\%), giddiness (1.04\%), slurring of speech (0.52 \%) and dry tongue (0.52\%) respectively.

\section{Covid-19 Patients with Comorbidities}

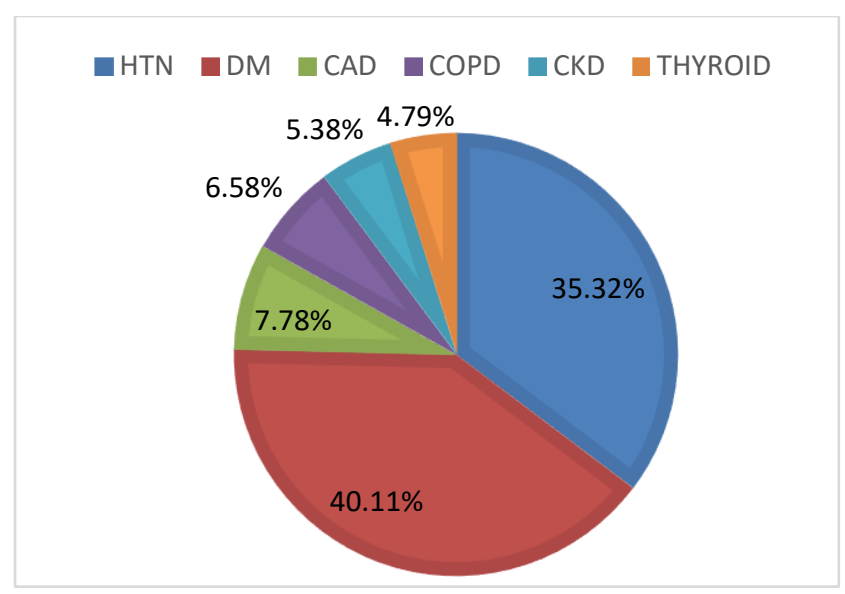

Figure 5: Comorbidity in percentage

The most common comorbidity observed in the SARS-COV 2 positive patients was DM $40.11 \%$ and HTN 35.32\%. A total of $7.78 \%$ had CAD, $6.58 \%$ had COPD, $5.38 \%$ had CKD and $4.79 \%$ had Thyroid.

\section{Percentage of Patients with and without Comorbidity}

WITH COMORBIDITY $\square$ WITHOUT COMORBIDITY

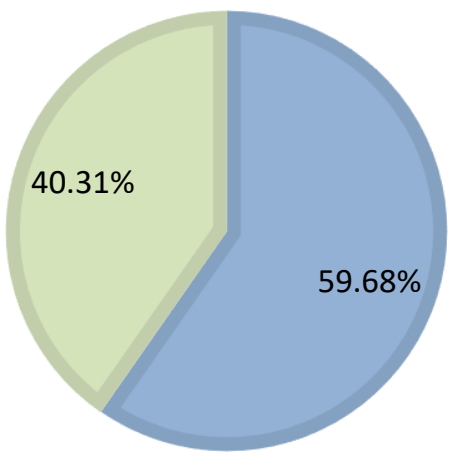

Figure 6: Percentage of Patients with and without Comorbidities

The patients with a comorbid condition were $59.68 \%$ and without co-morbidities were $40.31 \%$. This may depict that the patients with a comorbid condition may be more susceptible to the infection due to their altered physiological conditions.

\section{The difference in CT-Chest score of Patients without a Comorbid condition}

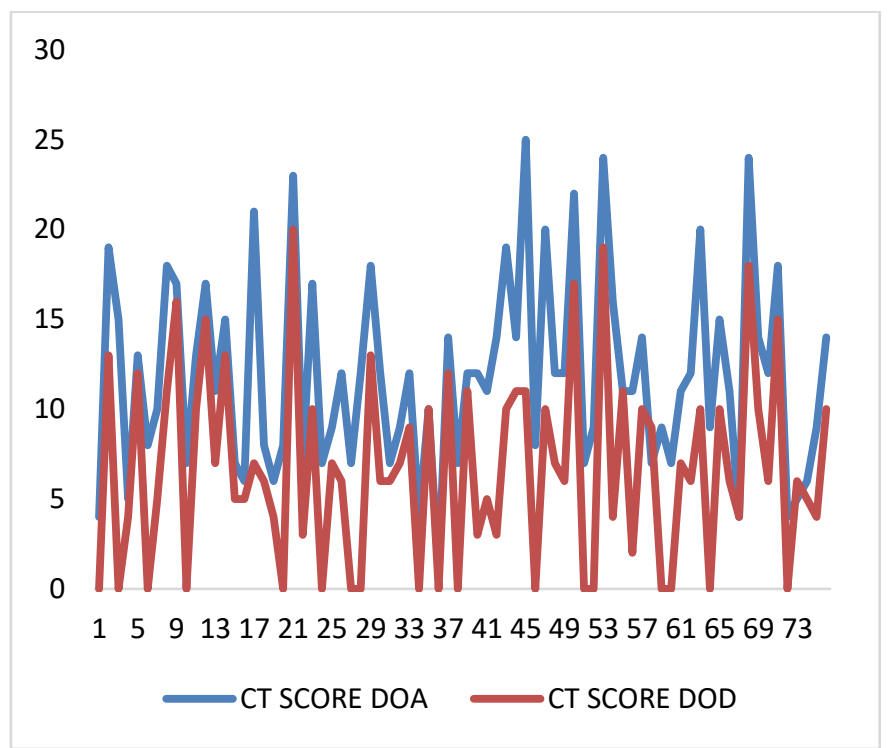

Figure 7: Difference in CT- Chest score of patients without a comorbid condition on admission and at the time of discharge.

The CT Chest score of the nil comorbid patients with a laboratory-confirmed SARSCOV-2 infection improved significantly during the date of discharge. This group of patients was also observed to have a faster recovery rate.

\section{Difference in CT-Chest score of Patients with a Comorbid condition}

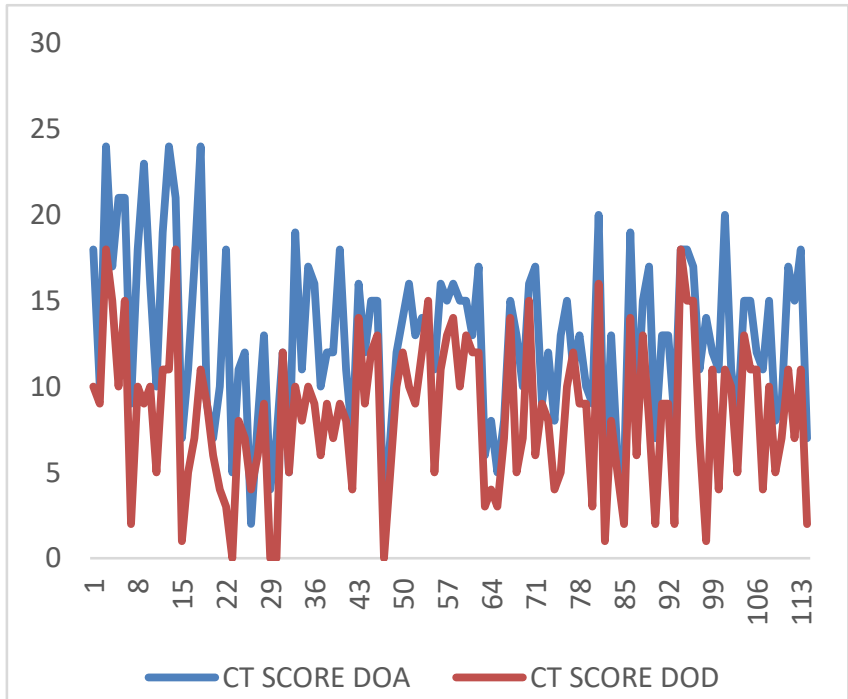

Figure 8: Mean Difference in CT- Chest score of patients with a comorbid condition on admission and at the time of discharge.

The CT Chest score of the comorbid SARS COV-2 infected patients was observed to be more severe when compared to those with nil comorbidities. Here, the CT Chest findings showed a more predominant involvement of both lungs with GGO (Ground glass opacity) in most of the patients. The recovery rate among this group was also observed to be delayed. 
Mean Comparison of CT Chest Score of Patients with and without Comorbid Conditions

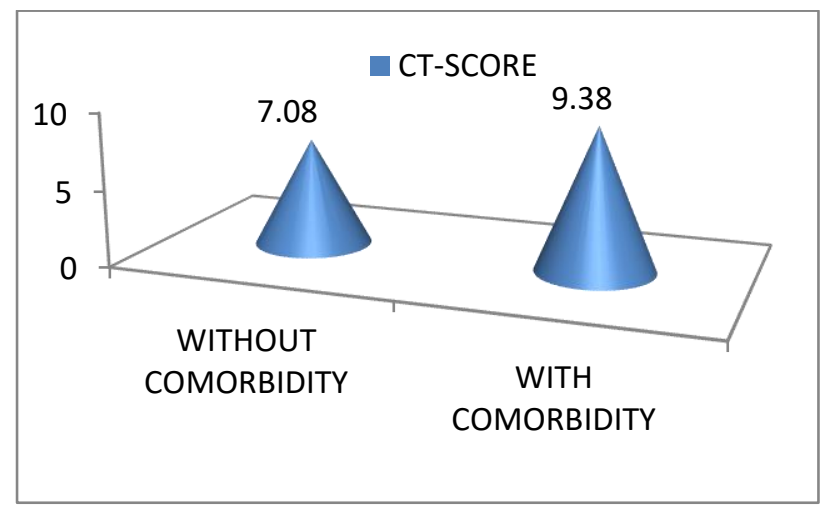

Figure 9: Mean Comparison of CT Chest score of patients with and without comorbid conditions.

The graphical representation depicts that the CT Score of the COVID-19 comorbid patients was higher (9.38) when compared to those without comorbidities (7.08). These findings may further also indicate that the comorbid patients were at an increased risk for severity in illness due to the infection and its associated complications.

\section{Duration of hospital stay in both groups}

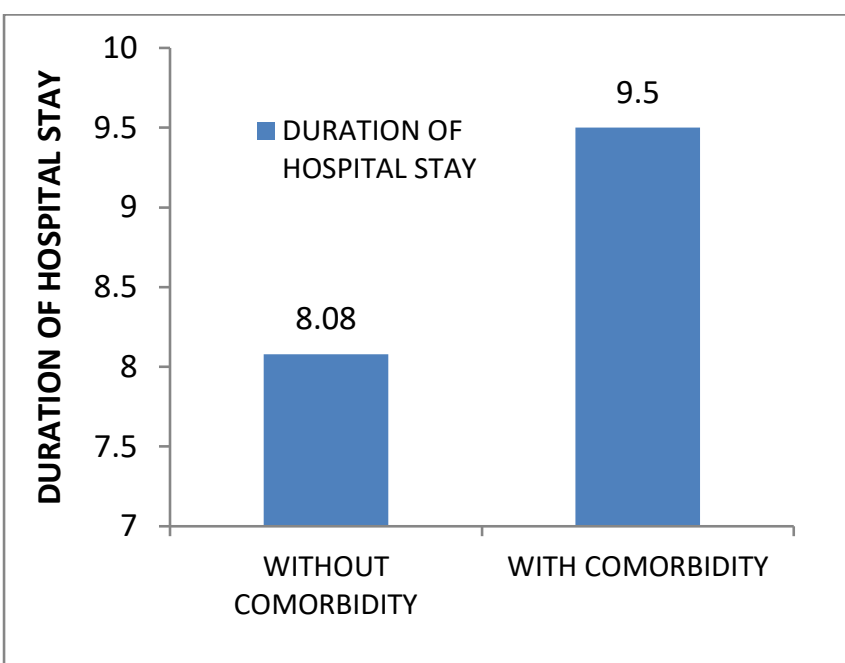

Figure 10: Mean Comparison of hospital stay on patients with and without comorbid conditions

Those subjects with a comorbid condition were observed to have a longer duration of hospitalization due to their severity in illness when compared to those without comorbidities. Here those with a comorbid condition and those without a comorbid condition were seen to have an average of 9.5 days and 8.08 days of hospital stay respectively.

\section{Mean Difference of RT-PCR in both groups}

The RT- PCR reports showed that those with and without a comorbid condition took average days of 10.04 and 7.44 in order to attain a negative RT-PCR Report. This may also indicate that SARS COV-2 infected comorbid population took a long time for recovery due to the infection.

\section{AVG DAYS FOR A NEGATIVE RT-PCR}

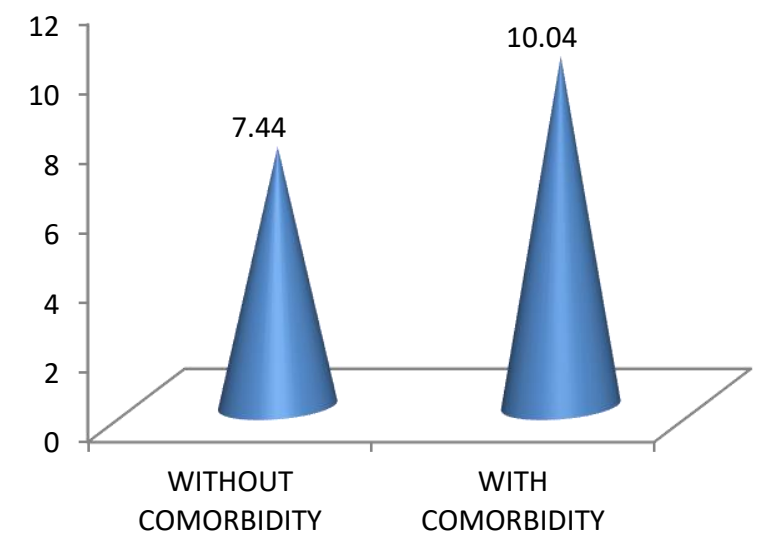

Figure 11: RT-PCR of Covid-19 patients

\section{DISCUSSION}

Since the outbreak of Covid-19 infectious disease many studies have reported that old age along with the presence of a comorbid condition may increase the severity of illness and recovery rates in the Covid-19 patients. ${ }^{16}$ In this study, 400 Covid-19 patients were included. After considering the inclusion and exclusion criteria total population of 191 moderately ill Covid-19 patients both with and without comorbidities were considered for the study. Gender distribution in percentage among the study population showed that the males were higher with $73.29 \%$ (140 males) and females comprised of about only $26.7 \%$ (51 females). Guido laccarino et al., 2020 reported in their study that, among the COVID 19 patients admitted to 26 hospitals, the male population was higher (64\%) and at least one preexistting condition was observed in $73.4 \%$ of the patients, with hypertension being the most represented. ${ }^{17}$

With the increase in age along with the presence of comorbidities, the risk of complications and severity in COVID-19 patients may also increase. Luigi Palmieri et al., 2020 in their study showed that older adults, especially those above 65 years presented with a higher number of comorbidities compared to those below 65 years. The incidence rate of ischemic heart disease, atrial fibrillation, heart failure, stroke, hypertension, dementia, COPD, and chronic renal failure was higher in older patients. ${ }^{18}$ Here, Covid-19 infection was found to be more prevalent between the age group of 51- 60 (26.17) years and the least were observed in the age group between 21-30 (2.09) years. The major complaints observed were fever (20.91\%), cough (16.73), myalgia (13.09\%) followed breathing difficulty (9.17\%). Rui Han et al., 2020 study showed the early clinical and laboratory findings of COVID-19 pneumonia were fever, dry cough, fatigue, elevated Creactive protein level and the early $\mathrm{CT}$ findings showed ground-glass opacities in the lungs. ${ }^{19}$

In our study among the underlying co-morbidities, the most common were DM (40.11\%), HTN (35.32\%), CAD (7.78 \%), COPD (6.58\%), CKD (5.38\%) and then thyroid (4.79\%). Ting 
Guo et al.,2021 in his study concluded that DM patients with COVID-19 may be prone to severe disease. High $\mathrm{HbA1C}$ levels and proteinuria could be major risk factors for the development of severe COVID-19 in DM patients. ${ }^{20,21}$ Our study also concluded that the percentage of patients with a comorbid condition was higher (59.68\%) than those without a comorbid condition (40.31\%). Xiaochen Li et al., 2020 in their study summarized those patients with hypertension, high lactate dehydrogenase level and geriatric category need careful observation to prevent the severity of illness in COVID-19 patients. ${ }^{22}$

CT Chest imaging plays a major role in the diagnosis and management of COVID -19 infections. In our study, the comorbid patients were seen to have a higher CT Chest Score when compared to patients without comorbidities. Here, 5.157 was the mean average of CT- Chest Score with nil comorbidities and 9.377 was the mean average of those with comorbidities, which indicates that those with a comorbid condition were affected severely. The mean reduction in CT- Chest Score in the comorbid and nilcomorbid was found to be $9.38 \pm 2.85$ and $7.08 \pm 2.89$ and was significant statistically. Islam $\mathrm{MN}$ et al., findings suggest that comorbid conditions may increase the risk of inhospital mortality despite low CT Chest severity score in COVID-19 infection when compared to non-comorbid patients. ${ }^{23}$

In our study, the duration of hospitalization of comorbid patients when compared to non-comorbid was also longer indicating that the comorbid patients took more time for recovery than those without comorbidities. Nicolai Haase et al., 2020 in the study of a population-based cohort in ICU patients with COVID-19 showed that male gender, age, and chronic co-morbidities, in particular chronic pulmonary disease, were associated with an increased stay in the hospital and death. ${ }^{24}$ The mean reduction in hospital stay in the comorbid and nil comorbid groups was found to be 9.50 \pm 2.34 and $8.08 \pm 1.71$ after the appropriate management done to relieve the condition and was found to be statistically significant. Rodrigo B Serafim et al., 2020 systematic review, including approximately 69000 ICU patients, concluded that COVID-19 infection in critically ill patients was associated with a greater need for lifesustaining interventions and prolonged length of ICU admissions. $^{25}$

The mean reduction in RT-PCR was $10.04 \pm 2.95$ and $7.44 \pm 2.33$ in the comorbid and nil comorbid groups respectively. The results, therefore, showed a statistical significance of $<0.0001$. Tony Zitek et al., 2020 in their study includes the importance of doing an RT-PCR test in the suspected Covid-19 population and made recommendations on it. ${ }^{26} \mathrm{Ki}$ Ho Hong et al., 2020 describes the importance of doing a real-time reverse transcriptionPCR as a reliable method for COVID-19 diagnosis around the world. ${ }^{27}$

\section{CONCLUSION}

It has been observed that Covid-19 patients with an underlying chronic illness are more likely to get infected and become severely ill. Thus, patients with comorbidities may have a more deteriorating outcome when compared to patients with nil comorbidities. COVID-19 patients with a medical history of hypertension, diabetes, chronic lung disease and cardiovascular disease have shown poor clinical outcomes and most often end up with worsening prognoses such as ARDS and pneumonia. The geriatric patients in longterm care facilities and the chronically ill patients are not only at risk, but there may also be a significantly increased risk in mortality among these populations. However, the symptoms of COVID-19 varied from mild to severe respiratory illness, which might require intubation or mechanical ventilation. Considering there is a period where the patient remains asymptomatic for about 2 and 14 days (incubation period), an early diagnosis would be hard. Hence, patients with comorbidities should take all the possible precautions to avoid getting infected with SARS CoV2. These inevitable precautions include regular hand washing with soap and water or with an alcohol-based hand sanitiser, limiting person-to-person contact, social distancing and wearing a face mask in public places.

\section{LIST OF ABBREVIATIONS}

ARDS- Acute Respiratory Distress Syndrome

\section{CAD- Coronary Artery Disease}

CKD- Chronic Kidney Disease

COPD- Chronic Obstructive Pulmonary Disease

CT-Computed Tomography

DM- Diabetes Mellitus

GGO -Ground Glass Opacity

HCoV-229E- Human Corona Virus 229 E

HCoV-HKU1-Human Corona Virus HKU1

HCoV-NL63-Human Corona Virus NL 63

HCoVOC43 - Human Corona Virus OC 43

HTN- Hypertension

ICU- Intensive Care Unit

MERS COV- Middle East Respiratory Corona Virus

RT-PCR- Real-Time Polymerase Chain Reaction

SARS- COV-2 - Severe Acute Respiratory Syndrome Coronavirus 2

\section{DECLARATIONS}

\section{Ethics Approval and Consent to Participate}

Written informed consent was signed by all study participants. The study approval was taken from the Institutional Ethical Committee (IEC), Vivekanandha Medical Care Hospital, Elyampalayam, Tiruchengode, 


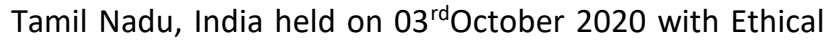
Committee number - SVCP/IEC/OCT/2020/42.

\section{Consent for Publication}

Not applicable

\section{Availability of Data and Material}

All data generated or analyzed during this study are included in this published article

\section{Competing Interest}

The author declares that they have no competing interests

\section{Funding}

$\mathrm{Nil}$

\section{Authors Contributions}

PSN and JP contributed for the idea of study and work proposal, protocol and supervision, SN, NW, NJ collected the patient data, consent for the study and documentation regarding COVID-19 patients and SP, TN was the contributors for analyzing, statistical analysis interpreting and writing the manuscript. "All authors read and approved the manuscript".

\section{Acknowledgement}

We gratefully acknowledge the Doctors of Pulmonology, Vivekanandha Medical Care Hospital, Elayampalayam, Tiruchengode, Tamil Nadu, India for their support.

\section{REFERENCES}

1. Noor FM, Islam MM. Prevalence and Associated Risk Factors of Mortality Among COVID-19 Patients: A Meta-Analysis. J Community Health. 2020;45(6):1270-1282. DOI: 10.1007/s10900-020-00920-x. PMID: 32918645.

2. Poblador-Plou B, Carmona-Pírez J, Loakeim-Skoufa I, PoncelFalcó A, Bliek-Bueno K, Cano-Del Pozo M, Gimeno-Feliú LA, González-Rubio F, Aza-Pascual-Salcedo M, Bandrés-Liso AC, Díez-Manglano J, Marta-Moreno J, Mucherino S, GimenoMiguel A, Prados-Torres A, EpiChron Group. Baseline Chronic Comorbidity and Mortality in Laboratory-Confirmed COVID19 Cases: Results from the PRECOVID Study in Spain. Int J Environ Res Public Health.2020;17(14):5171. DOI:10.3390/ijerph17145171. PMID: 32709002.

3. Guan WJ, Liang WH, Zhao Y, Liang HR, Chen ZS, Li YM, Liu XQ Chen RC, Tang CL, Wang T, Ou CQ, Li L, Chen PY, Sang L, Wang W, Li JF, Li CC, Ou LM, Cheng B, Xiong S, Ni ZY, Xiang J, Hu Y, Liu L, Shan $\mathrm{H}$, Lei $\mathrm{CL}$, Peng $Y X$, Wei L, Liu Y, Hu YH, Peng P, Wang JM, Liu JY, Chen Z, Li G, Zheng ZJ, Qiu SQ, Luo J, Ye CJ, Zhu SY, Cheng LL, Ye F, Li SY, Zheng JP, Zhang NF, Zhong NS, He JX; China Medical Treatment Expert Group for COVID-19. Comorbidity and its impact on 1590 patients with COVID-19 in China: a nationwide analysis. Eur Respir J.2020;55(5):2000547. DOI:10.1183/13993003.00547-2020. PMID:32217650.

4. Jakhmola S, Indari O, Baral B, Kashyap D, Varshney N, Das A, Chatterjee S, Jha HC. Comorbidity Assessment Is Essential During COVID-19 Treatment. Frontiers in Physiology. 2020;11:984. DOI: 10.3389/fphys.2020.00984. PMID: 32903640 .
5. Hu Z, Song C, Xu C, Jin G, Chen Y, Xu X, Ma H, Chen W, Lin Y, Zheng Y, Wang J, Hu Z, Yi Y, Shen H. Clinical characteristics of 24 asymptomatic infections with COVID-19 screened among close contacts in Nanjing, China. Sci China Life Sci. 2020;63(5):706-711. DOI:10.1007/s11427-020-1661-4. PMID: 32146694.

6. Chang TH, Wu JL, Chang LY. Clinical characteristics and diagnostic challenges of pediatric COVID-19: A systematic review and meta-analysis. J Formos Med Assoc. 2020;119(5):982-989. DOI: 10.1016/j.jfma.2020.04.007. PMID: 32307322.

7. Wang B, Li R, Lu Z, Huang Y. Does comorbidity increase the risk of patients with COVID-19: evidence from meta-analysis. Aging (Albany NY). 2020;12(7):6049-6057. DOI: 10.18632/aging.103000. PMID: 32267833.

8. Sanyaolu A, Okorie C, Marinkovic A, Patidar R, Younis K, Desai P, Hosein Z, Padda I, Mangat J, Altaf M. Comorbidity and its Impact on Patients with COVID-19. SN Comprehensive Clinical Medicine. 2020;25:1-8. DOI: 10.1007/s42399-02000363-4. PMID: 32838147.

9. Laccarino G, Grassi G, Borghi C, Ferri C, Salvetti M, Volpe M; SARS-RAS Investigators. Age and Multimorbidity Predict Death Among COVID-19 Patients: Results of the SARS-RAS Study of the Italian Society of Hypertension. Hypertension. 2020;76(2):366-372.

DOI: 10.1161/HYPERTENSIONAHA.120.15324. PMID: 32564693.

10. Owen RK, Conroy SP, Taub N, Jones W, Bryden D, Pareek M, Faull C, Abrams KR, Davis D, Banerjee J. Comparing associations between frailty and mortality in hospitalised older adults with or without COVID-19 infection: a retrospective observational study using electronic health records. Age Ageing. 2021;50(2):307-316.DOI: 10.1093/ageing/afaa167. PMID: 32678866.

11. Ejaz $H$, Alsrhani $A$, Zafar $A$, Javed $H$, Junaid $K$, Abdalla $A E$, Abosalif KOA, Ahmed Z, Younas S. COVID-19 and comorbidities: Deleterious impact on infected patients. J Infect Public Health. 2020;13(12):1833-1839. DOI: 10.1016/j.jiph.2020.07.014 PMID: 32788073.

12. Song J, Zeng $M$, Wang $H$, Qin $C$, Hou HY, Sun ZY, Xu SP, Wang GP, Guo CL, Deng YK, Wang ZC, Ma J, Pan L, Liao B, Du ZH, Feng QM, Liu Y, Xie JG, Liu Z. Distinct effects of asthma and COPD comorbidity on disease expression and outcome in patients with COVID-19. Allergy. 2021;76(2):483-496. DOI:10.1111/all.14517. PMID: 32716553.

13. Izquierdo JL, Almonacid C, González Y, Del Rio-Bermudez C, Ancochea J, Cárdenas R, Lumbreras S, Soriano JB. The impact of COVID-19 on patients with asthma. Eur Respir J. 2021;57(3):2003142. DOI:10.1183/13993003.03142-2020. PMID: 33154029.

14. Tang O, Bigelow BF, Sheikh F, Peters M, Zenilman JM, Bennett R, Katz MJ. Outcomes of Nursing Home COVID-19 Patients by Initial Symptoms and Comorbidity: Results of Universal Testing of 1970 Residents. J Am Med Dir Assoc.2020;21(12):1767-1773.e1. DOI: 10.1016/j.jamda.2020.10.011. PMID: 33153910.

15. Guo L, Shi Z, Zhang Y, Wang C, Do Vale Moreira NC, Zuo H, Hussain A. Comorbid diabetes and the risk of disease severity or death among 8807 COVID-19 patients in China: A metaanalysis. Diabetes Res Clin Pract.2020;166:108346. DOI: 10.1016/j.diabres.2020.108346. PMID: 32710998. 
16. Zhou F, Yu T, Du R, Fan G, Liu Y, Liu Z, Xiang J, Wang Y, Song B, Gu X, Guan L, Wei Y, Li H, Wu X, Xu J, Tu S, Zhang Y, Chen $H, C a o B$. Clinical course and risk factors for mortality of adult inpatients with COVID-19 in Wuhan, China: a retrospective cohort study. Lancet. 2020;395(10229):1054-1062. DOI: 10.1016/S0140-6736(20)30566-3. PMID: 32171076.

17. Laccarino G, Grassi G, Borghi C, Ferri C, Salvetti M, Volpe M; SARS-RAS Investigators. Age and Multimorbidity Predict Death Among COVID-19 Patients: Results of the SARS-RAS Study of the Italian Society of Hypertension. Hypertension. 2020;76(2):366-372.

DOI: 10.1161/HYPERTENSIONAHA.120.15324.PMID: 32564693.

18. Palmieri L, Vanacore N, Donfrancesco C, Lo Noce C, Canevelli M, Punzo O, Raparelli V, Pezzotti P, Riccardo F, Bella A, Fabiani M, D'Ancona FP, Vaianella L, Tiple D, Colaizzo E, Palmer K, Rezza G, Piccioli A, Brusaferro S, Onder G; Italian National Institute of Health COVID-19 Mortality Group. Clinical Characteristics of Hospitalized Individuals Dying With COVID-19 by Age Group in Italy. J Gerontol A Biol Sci Med Sci. 2020;75(9):1796-1800. DOI: 10.1093/gerona/glaa146. PMID: 32506122 .

19. Han R, Huang L, Jiang H, Dong J, Peng H, Zhang D. Early Clinical and CT Manifestations of Coronavirus Disease 2019 (COVID19) Pneumonia. AJR Am J Roentgenol. 2020;215(2):338-343. DOI: 10.2214/AJR.20.22961. PMID: 32181672.

20. Guo T, Shen Q, Ouyang X, Guo W, Li J, He W, Yu B, Wu C, Zhou $\mathrm{Z}$, Luo H, Peng H. Clinical Findings in Diabetes Mellitus Patients with COVID-19. J Diabetes Res. 2021;21:7830136. DOI: 10.1155/2021/7830136. PMID: 33506052.

21. Muniyappa R, Gubbi S. COVID-19 pandemic, coronaviruses, and diabetes mellitus. Am J Physiol Endocrinol Metab. 2020;318(5):E736-E741. DOI: 10.1152/ajpendo.00124.2020. PMID: 32228322.
22. Li X, Xu S, Yu M, Wang K, Tao Y, Zhou Y, Shi J, Zhou M, Wu B, Yang Z, Zhang C, Yue J, Zhang Z, Renz H, Liu X, Xie J, Xie M, Zhao J. Risk factors for severity and mortality in adult COVID19 inpatients in Wuhan. J Allergy Clin Immunol. 2020;146(1):110-118. DOI: 10.1016/j.jaci.2020.04.006. PMID: 32294485.

23. Islam MN, Dipi RM, Mostafa SN, Datta A. Progression of Disease in COVID-19 Patients Evaluated by Chest CT Imaging and Correlated with Clinical Parameters. Mymensingh Med J. 2021;30(1):182-188. PMID: 33397872.

24. Haase N, Plovsing R, Christensen S, Poulsen LM, Brøchner AC, Rasmussen BS, Helleberg M, Jensen JUS, Andersen LPK, Siegel $\mathrm{H}$, Ibsen $\mathrm{M}$, Jørgensen $\mathrm{V}$, Winding $\mathrm{R}$, Iversen $\mathrm{S}$, Pedersen HP, Madsen J, Sølling C, Garcia RS, Michelsen J, Mohr T, Mannering A, Espelund US, Bundgaard H, Kirkegaard L, Smitt M, Buck DL, Ribergaard NE, Pedersen HS, Christensen BV, Perner A. Characteristics, interventions, and longer term outcomes of COVID-19 ICU patients in Denmark-A nationwide, observational study. Acta Anaesthesiol Scand. 2021;65(1):68-75. DOI: 10.1111/aas.13701.PMID: 32929715.

25. Serafim RB, Póvoa P, Souza-Dantas V, Kalil AC, Salluh JIF. Clinical course and outcomes of critically ill patients with COVID-19 infection: a systematic review. Clin Microbiol Infect. 2021;27(1):47-54. DOI: 10.1016/j.cmi.2020.10.017. PMID: 33190794.

26. Zitek T. The Appropriate Use of Testing for COVID-19. West J Emerg Med. 2020;21(3):470-472. DOI: 10.5811/westjem.2020.4.47370. PMID: 32302278.

27. Hong KH, Lee SW, Kim TS, Huh HJ, Lee J, Kim SY, Park JS, Kim GJ, Sung H, Roh KH, Kim JS, Kim HS, Lee ST, Seong MW, Ryoo $\mathrm{N}$, Lee $\mathrm{H}$, Kwon KC, Yoo CK. Guidelines for Laboratory Diagnosis of Coronavirus Disease 2019 (COVID-19) in Korea. Ann Lab Med. 2020;40(5):351-360. DOI: 10.3343/alm.2020.40.5.351. PMID: 32237288.

Source of Support: The author(s) received no financial support for the research, authorship, and/or publication of this article.

Conflict of Interest: The author(s) declared no potential conflicts of interest with respect to the research, authorship, and/or publication of this article.

For any question relates to this article, please reach us at: editor@globalresearchonline.net

New manuscripts for publication can be submitted at: submit@globalresearchonline.net and submit_ijpsrr@rediffmail.com 